\title{
Do healthier lifestyles lead to less utilization of healthcare resources?
}

\author{
I-Chen Lee ${ }^{1}$, Chao-Sung Chang ${ }^{2}$ and Pey-Lan Du ${ }^{3^{*}}$
}

\begin{abstract}
Background: Governments are urged to determine methods to control the use of medical resources and curb the rise of healthcare costs. The question is, do health behaviors have an impact on the use of medical resources? This study aims to identify and understand the difference in the number of outpatient visits and health examinations based on various health behaviors and to determine whether patients seek medical care for illness from the same physicians.

Methods: This study used the dataset derived from the Department of Budget, Accounting and Statistics of Kaohsiung, Taiwan in 2005. Persons older than 15 years were surveyed using an on-site questionnaire. A total of 2911 persons were enrolled in this study. Independent $t$-tests, chi-square tests, one-way ANOVA, multiple linear regression and binominal logistic regression were used in the data analysis.

Results: The regression model for the frequency of doctor visits, health examinations, and whether the same physician is sought for medical care has demonstrated significant correlations with gender, age and education-level variables. Four health behaviors (i.e., exercise habits, dietary habits, regular blood pressure measurement, drinking habits) exhibited a significant correlation with healthcare utilization $(P<0.05)$.

Conclusions: Healthy lifestyles lead to an increase in the utilization of preventive health services. However, there is not much significantly reducing the number of outpatient visits in people with health behaviors. Specifically, people with regular exercise habits and who take their blood pressure measurement regularly have an increased number of outpatient visits. It is suggested that more available and accessible health consultation services be provided to inculcate in the general public the importance of maintaining a healthy lifestyle.
\end{abstract}

Keywords: Utilization of healthcare resources, Healthy lifestyle, Preventive health services

\section{Background}

There is a steady increase in the utilization of national healthcare resources because of the aging population in recent years, along with the rapid increase in healthcare costs. Governments are urged to determine methods to control the use of healthcare resources and curb the rise of healthcare costs [1-3]. Healthcare resources include medical-related services (i.e., outpatient visits, emergency care, and hospitalization) and preventive services (i.e., health examinations). Usually, medical-related and preventive services are both provided by professionals from general hospitals or clinics, however, the goals of thoses two services are different. People receive medical-

\footnotetext{
* Correspondence: peylandu@nqu.edu.tw

${ }^{3}$ Department of Sport and Leisure, National Quemoy University, No.1, Daxue

Rd., Jinning Township, Kinmen County, Kinmen 892, Taiwan

Full list of author information is available at the end of the article
}

related services to relieve the discomfort or to slow down the progress of the disease when they have obvious physical symptoms. In contrast, preventive services are provided to ensure that healthy people who do not suffer from any physical discomfort and do not need any specific treatments, or people who are at high-risk of having certain diseases don't get sick. It is also done to detect early any symptoms of diseases. The research indicates that the probability of being hospitalized and the number of outpatient or emergency visits decreases as more preventive healthcare services are provided, and this may reduce healthcare costs [4-6].

Taiwan established the National Health Insurance in 1995; the policy eliminates the financial barriers encountered by most people during medical treatment and provides many preventive health-related services free of 
charge such as physical examinations for those over the age of 40. Meanwhile, the National Health Insurance Administration (NHIA) aggressively promotes the system of having a primary physician for family care since 2003 [7]. People are strongly suggested to seek medical care from the same physician when they are sick, so that the whole family history of health and diseases can be traced and monitored. In reference to the Western system of Family Medicine, people are encouraged to look for a reliable physician in the nearby community when they need primary medical care. The family physician may refer their clients to specific medical care specialists when advanced care is needed, and this physician will also obtain the necessary information or feedback through this referral system, which may enhance the preventive health care services and strengthen the network of primary medical care for the patients. As previously metioned, in order to slow down the increase in healthcare costs, it is necessary to provide adequate preventive healthcare services and to improve the utilization of these services. Most studies [8-11] have explored the utilization of healthcare resources, which focused on issues such as the frequency of visits to outpatient and emergency clinics, the number of patients admitted, and the length of stay for each hospitalization as well. However, there are few studies reviewing the utilization of preventive health care services and the related issues.

Andersen claimed that people's health status is the most important determining factor in the utilization of health resources [12]. Some researchers [13-16] also reported that health conditions improve as people become more health conscious and maintain a healthy lifestyle, consequently, the use of medical resources decreases. Purvis (2013) [17] investigated the factors that influence health conditions, and the results showed that health behaviors have a significant effect on health conditions. Also, health behaviors were a major determinant of morbidity and mortality in the US [18]. Thus, the health behaviors, the health status, the utilization of medical resources, and the mortality rate for certain diseases are correlated significantly. Few individual studies provide comprehensive compilations of numerous health behaviors and consider them to be the main research topic. Most studies [19-21] have only addressed and explored on the risks of one or two health behaviors in relation to sickness, whereas the health behaviors have not been the main topic for the said studies.

In order to curb the rise of medical costs, the issues regarding the utilization of medical resources and preventive health care services shall be crucially addressed. In advance, this study aims to clarify what kinds of health behaviors might reduce the utilization of medical resources, and whether the health behaviors affect the utilization of preventive health care services as well.
Thus, a survey on people's health status in a specific region were conducted and analyzed in this study for two purposes: (1) to understand the relationship between health behaviors and the utilization of health care resources (i.e., the frequency of outpatient visits and health examinations), and (2) to explore how the specific type of health behaviors affect the utilization of health care resources.

\section{Methods}

In 2005, an annual survey was conducted by the Department of Budget, Accounting and Statistics of Kaohsiung, using a well-designed and structured questionnaire, to study the correlation among lifestyles, utilization of health care resources, and the health status of the citizens in Kaohsiung. All questions derived from the literature were developed by the research committee and verified by a panel of professional experts. The panel of professional experts reached a $94 \%$ item-by-item agreement on content validity and appropriateness of wording.

Kaohsiung is the second biggest city in Taiwan. A twostage stratified random sampling was used in this study. In the first stage, the townships were randomly selected from all the eleven administration districts in the city of Kaohsiung. In the second stage, the households were then randomly selected from the sampled townships. There were a total of 2911 people aged over 15 years in these sampled households who have been recruited as the subjects in this study. A trained interviewer was sent to assist the selected citizens to complete the questionnaire during face-to-face interviews. All the interviewers and researchers were fully oriented and highly trained in advance of the study for increased objectivity.

The secondary data analysis was conducted in the course of this study. The primary data were derived from the data base of the related government department. These use of data has been granted an exemption from requiring ethics approval according to the regulations set by the Ministry of Justice in Taiwan (http:// mohwlaw.mohw.gov.tw/FLAW/FLAWDAT0202.aspx? lsid=FL066232). There are four types of variables in this study: demographic information, health behaviors, current health status, and utilization of health care resouces. Detailed descriptions of each type were provided as follows:

\section{Demographic information}

Demographic factors including sex, age, education level,and marital status were recorded.

Health behaviors

The respondents were provided with a list of dietary habits, exercise habits, behavioral habits such as smoking, drinking and betel nut chewing, and blood pressure measuring. The respondents then completed 
this questionnaire by truly reflecting their daily living habits and lifestyle. The dietary habits were recorded using 5 questions as to whether the respondents had the following habits: "eating breakfast", "fixed number of meals and regular mealtime", " 5 varieties of vegetables or fruits a day", "maintaining a low salt, low sugar and low fat diet", and "being aware of the description and branding of food products". The respondents were asked the following questions regarding health related behaviors: "Do you care about your own health condition?", "Do you measure your blood pressure regularly?", and "Have you exercised regularly in the past 3 months?" The habits of smoking, drinking and betel nut chewing were assessed by the questions, "Do you have a habit of smoking, drinking and betel-nut chewing?"

Current health status

The presence of any physician-diagnosed chronic illness was ascertained by the following question about each individual's current health status: "Are you suffering from any chronic diseases including hypertension, diabetes, cardiovascular disease, musculoskeletal disease, respiratory disease, gout, and cancer?"

Utilization of health care resources Information on the individual's utilization of health care resources were obtained from the questions about the frequency of outpatient visits in the past 3 months and the utilization of preventive healthcare services, as well as the number of health exams taken in the past 3 years and whether individuals seek medical care for illness from the same physician. The footnote "diseaserelated outpatient visits" pertains to the question on the number of hospitals or clinics visited. The footnote, "disease-related examinations which were done in hospitals or clinics were excluded" pertains to the question on the number of health examinations taken. In the meanwhile, a list of all kinds of health examinations was provided as reference for clarification and to discern the utilization of these two types of health care resources. The number of health examinations has not been counted into the number of outpatient visits.

The statistical analyses were performed using SPSS (Statistical Product and Service Solutions) software, version 19.0. Independent $t$-tests, chi-square tests and one-wayANOVA (analysis of variance) were used to examine the utilization of health care resources in terms of specific demographic characteristics, health status, and health behaviors. The demographic variables and health status were adjusted in multivariate analysis of regression to further clarify the association between health behaviors and the utilization of health care resources. A multiple linear regression model was performed to examine the association of health behaviors (independent variable), the frequency of outpatient visits (dependent variable), and the number of health exams taken (dependent variable). A binominal logistic regression model was used to determine the odds ratio among the groups of individuals seeking medical care for illness from the same physician (dependent variable). Additionally, the demographics and health status were considered as independent variables in the above regression model. In order to investigate the association between health behaviors and the utilization of health care resources more globally and comprehensively, all health behaviors were computed in the regression model. Simultaneously, the collinearity diagnosis was performed to assess whether the severity of association among health behaviors exist.

\section{Results}

The data regarding the difference among the various demographic characteristics in the number of outpatient visits and health examinations and whether patients seek medical care for illness from the same physician is shown in Table 1. The results show that women seek medical treatment more frequently on a yearly basis and are more likely to seek medical care from the same physician. However, they undergo health examinations less frequently. Married individuals tend to go to outpatient visits and health examinations more frequently, and they prefer to be seen by the same physician for an illness. Scheffe's post hoc comparison indicates that people 45 years and older show a significant increase in the frequency of outpatient visits and health examinations; these patients have a greater chance of seeking medical care from the same doctor. Scheffe's post hoc comparison identifies that those with an elementary or lower education level tend to visit doctors more often, undergo health exams more frequently, and are more likely to visit the same doctor for illness. Those currently suffering from diseases frequently visit outpatient clinics, perform health examinations more often and receive medical care for illness from the same physician. These findings are statistically significant $(P<0.05)$.

Further analyses indicate that health behaviors differ between the number of outpatient visits, the frequency of obtaining health exams, and seeking medical attention for illness from the same physician. Six health behaviors are related to health exams, whereas four are related to the frequency of outpatient visits and seeking medical care from the same physician $(P<0.05)$. For example, compared to those without regular exercise habits, people who exercise regularly visit a physician more frequently (mean $=1.12$ v.s 0.91 ), they are more likely to take health exams (mean $=1.14$ v.s 0.70 ), and have a higher probability of seeking the same physician for medical care (41.7\%v.s31.6\%). The remaining health 
Table 1 The Association Between Demographic Characteristics And Healthcare Utilization

\begin{tabular}{|c|c|c|c|c|c|c|c|}
\hline \multirow[t]{3}{*}{ Variable } & \multirow{2}{*}{\multicolumn{2}{|c|}{$\begin{array}{l}\text { Number of outpatient } \\
\text { visits }\end{array}$}} & \multirow{2}{*}{\multicolumn{2}{|c|}{ Number of health exams }} & \multicolumn{3}{|c|}{ Seen by the same physicians } \\
\hline & & & & & \multirow{2}{*}{$\begin{array}{l}\text { Yes } \\
N(\%)\end{array}$} & \multirow{2}{*}{$\begin{array}{l}\text { No } \\
N(\%)\end{array}$} & \multirow[b]{2}{*}{$p$} \\
\hline & Mean (SD) & $p$ & Mean (SD) & $p$ & & & \\
\hline \multicolumn{8}{|l|}{ Gender } \\
\hline Male & $0.92(0.91)$ & $<0.001$ & $0.92(1.33)$ & 0.035 & $937(46.3)$ & $452(50.8)$ & 0.028 \\
\hline Female & $1.05(1.00)$ & & $0.82(1.18)$ & & $1085(53.7)$ & $437(49.2)$ & \\
\hline \multicolumn{8}{|l|}{ Marital Status } \\
\hline With Spouse & $1.07(0.99)$ & $<0.001$ & $1.00(1.33)$ & $<0.001$ & $1251(61.9)$ & $484(54.4)$ & $<0.001$ \\
\hline Without Spouse & $0.88(0.91)$ & & $0.67(1.10)$ & & $771(38.1)$ & $405(45.6)$ & \\
\hline \multicolumn{8}{|l|}{ Age } \\
\hline 15-18years & $1.50(1.93)$ & $<0.001$ & $0.36(0.78)$ & $<0.001$ & $138(6.8)$ & $94(10.6)$ & $<0.001$ \\
\hline 19-24years & $1.90(3.53)$ & & $0.47(0.80)$ & & $162(8.0)$ & $90(10.1)$ & \\
\hline 25-34years & $1.75(2.72)$ & & $0.62(1.09)$ & & $283(14.0)$ & $146(16.4)$ & \\
\hline 35-44years & $2.26(3.38)$ & & $0.72(1.22)$ & & $347(17.2)$ & $187(21.0)$ & \\
\hline 45-54years & $2.62(3.41)$ & & $0.98(1.27)$ & & $476(23.5)$ & $174(19.6)$ & \\
\hline 55-64years & $3.93(5.09)$ & & $0.92(1.17)$ & & $301(14.9)$ & $112(12.6)$ & \\
\hline$\geqq 65$ years & $4.78(4.98)$ & & $1.65(1.61)$ & & $315(15.6)$ & $86(9.7)$ & \\
\hline \multicolumn{8}{|l|}{ Education Level } \\
\hline Illiterate / Self Study & $5.63(6.31)$ & $<0.001$ & $1.29(1.49)$ & $<0.001$ & $145(7.2)$ & $49(5.5)$ & 0.015 \\
\hline Elementary & $4.00(5.04)$ & & $1.01(1.35)$ & & $317(15.7)$ & $111(12.5)$ & \\
\hline Junior High School & $2.60(3.58)$ & & $0.71(1.20)$ & & $287(14.2)$ & $134(15.1)$ & \\
\hline Senior High School & $2.23(3.20)$ & & $0.73(1.17)$ & & $656(32.4)$ & $339(38.1)$ & \\
\hline College/University & $2.21(3.05)$ & & $0.92(1.26)$ & & $563(27.8)$ & $237(26.7)$ & \\
\hline Graduate\& above & $1.93(2.10)$ & & $1.16(1.35)$ & & $54(2.7)$ & $19(2.1)$ & \\
\hline \multicolumn{8}{|l|}{ Disease } \\
\hline No & $0.66(0.74)$ & $<0.001$ & $0.67(1.13)$ & $<0.001$ & $1146(56.7)$ & $627(70.5)$ & $<0.001$ \\
\hline Yes & $1.51(1.04)$ & & $1.17(1.37)$ & & $876(43.3)$ & $262(29.5)$ & \\
\hline
\end{tabular}

Data from the structured questionnaire of the Department of Budget, Accounting and Statistics of Kaohsiung, Taiwan in 2005 weighted to be national representative

behaviors, in relationship to the frequency of outpatient visits, health exams and seeking medical care from the same physicians, are noted in Table 2.

The regression model for the frequency of outpatient visits, health examinations, and whether to seek medical care from the same physician (Table 3) shows significant correlation with gender, age and education-level variables. As shown in the results, four variables which include exercise habits, dietary habits (a low salt, low sugar, and low fat diet), regular blood pressure measurement and drinking habits correlate significantly with healthcare utilization $(P<0.05)$. When comparing the results with people who exercise regularly, those without regular exercise regimens are less likely to visit a physician, undergo health exams, and seek medical care for illness from the same physician (odds ratio, $\mathrm{OR}=0.70$, $95 \% \mathrm{CI}=0.58-0.83$ ). The individuals who do not follow healthy eating habits are more likely to visit physicians when compared to those with healthy eating habits. The individuals who do not check their blood pressure regularly are less likely to visit physicians and undergo health exams as compared to those who have regular blood pressure assessment. Those who drink regularly are less likely to seek medical care for illness from the same physician than those who do not drink (odds ratio, $\mathrm{OR}=$ $0.71,95 \% \mathrm{CI}=0.58-0.85)$. The results of collinearity diagnosis reveal that the severity of association among all independent variables do not reach a significant level to affect the statistical computation.

\section{Discussion}

This survey consists of various aspects of health behaviors in daily life and detailed information of the utilization of preventive health care resources, which may complete the perspective of the main issues that this study would like to address. Regarding the correlation between health behaviors and the utilization of health care resources, the univariate analysis indicates 
Table 2 The Association Between Individual Lifestyle and Healthcare Utilization

\begin{tabular}{|c|c|c|c|c|c|c|c|}
\hline \multirow[t]{3}{*}{ Variable } & \multirow{2}{*}{\multicolumn{2}{|c|}{$\begin{array}{l}\text { Number of outpatient } \\
\text { visits }\end{array}$}} & \multirow{2}{*}{\multicolumn{2}{|c|}{ Number of health exams }} & \multicolumn{3}{|c|}{ Seen by the same physicians } \\
\hline & & & & & \multirow{2}{*}{$\begin{array}{l}\text { Yes } \\
N(\%)\end{array}$} & \multirow{2}{*}{$\begin{array}{l}\text { No } \\
N(\%)\end{array}$} & \multirow[b]{2}{*}{$p$} \\
\hline & Mean (SD) & $p$ & Mean (SD) & $p$ & & & \\
\hline \multicolumn{8}{|c|}{ Exercise Habits } \\
\hline Yes & $1.12(1.01)$ & $<0.001$ & $1.14(1.36)$ & $<0.001$ & $843(41.7)$ & $281(31.6)$ & $<0.001$ \\
\hline No & $0.91(0.92)$ & & $0.70(1.15)$ & & $1179(58.3)$ & $608(68.4)$ & \\
\hline \multicolumn{8}{|l|}{ Breakfast } \\
\hline Yes & $0.99(0.97)$ & 0.984 & $0.87(1.25)$ & 0.185 & $1966(97.2)$ & $862(97.0)$ & 0.781 \\
\hline No & $0.99(0.85)$ & & $0.69(1.21)$ & & $56(2.8)$ & $27(3.0)$ & \\
\hline \multicolumn{8}{|c|}{ Regular meals } \\
\hline Yes & $0.99(0.96)$ & 0.905 & $0.88(1.26)$ & 0.001 & $1944(96.1)$ & $839(94.4)$ & 0.041 \\
\hline No & $1.00(1.04)$ & & $0.57(1.03)$ & & $78(3.9)$ & $50(5.6)$ & \\
\hline \multicolumn{8}{|c|}{5 servings of fruits\& vegetables } \\
\hline Yes & $0.98(0.95)$ & 0.036 & $0.66(1.13)$ & 0.001 & $1807(89.4)$ & $782(88.0)$ & 0.295 \\
\hline No & $1.10(1.04)$ & & $0.89(1.26)$ & & $215(10.6)$ & $107(12.0)$ & \\
\hline \multicolumn{8}{|c|}{ Dieting Habits } \\
\hline Yes & $0.98(0.96)$ & 0.098 & $0.89(1.26)$ & $<0.001$ & $1829(90.5)$ & $787(88.5)$ & 0.128 \\
\hline No & $1.08(1.03)$ & & $0.62(1.11)$ & & $193(9.5)$ & $102(11.5)$ & \\
\hline \multicolumn{8}{|c|}{ Aware of food packaging labels } \\
\hline Yes & $0.98(0.95)$ & 0.015 & $0.87(1.25)$ & 0.686 & $1860(92.0)$ & $815(91.7)$ & 0.833 \\
\hline No & $1.16(1.11)$ & & $0.83(1.30)$ & & $162(8.0)$ & $74(8.3)$ & \\
\hline \multicolumn{8}{|c|}{ Aware of self-health } \\
\hline Yes & $1.00(0.96)$ & 0.091 & $0.88(1.26)$ & $<0.001$ & $1953(96.6)$ & $858(96.5)$ & 1.000 \\
\hline No & $0.83(0.95)$ & & $0.45(1.00)$ & & $69(3.4)$ & $31(3.5)$ & \\
\hline \multicolumn{8}{|c|}{ Regular BP } \\
\hline Yes & $1.12(1.01)$ & $<0.001$ & $1.08(1.35)$ & $<0.001$ & $1337(66.1)$ & $520(58.5)$ & $<0.001$ \\
\hline No & $0.76(0.83)$ & & $0.49(0.94)$ & & $685(33.9)$ & $369(41.5)$ & \\
\hline \multicolumn{8}{|l|}{ Smoking } \\
\hline Yes & $0.97(0.99)$ & 0.496 & $0.88(1.33)$ & 0.780 & $552(27.3)$ & $262(29.5)$ & 0.247 \\
\hline No & $1.00(0.95)$ & & $0.86(1.22)$ & & $1470(72.7)$ & $627(70.5)$ & \\
\hline \multicolumn{8}{|l|}{ Drinking } \\
\hline Yes & $0.95(0.94)$ & 0.088 & $0.92(1.25)$ & 0.068 & $726(35.9)$ & $381(42.9)$ & $<0.001$ \\
\hline No & $1.01(0.97)$ & & $0.83(1.25)$ & & $1296(64.1)$ & $508(57.1)$ & \\
\hline \multicolumn{8}{|c|}{ Betel-Nut chewing } \\
\hline Yes & $0.91(0.90)$ & 0.098 & $0.80(1.31)$ & 0.320 & $235(11.6)$ & $105(11.8)$ & 0.933 \\
\hline No & $1.00(0.97)$ & & $0.87(1.25)$ & & $1787(88.4)$ & $784(88.2)$ & \\
\hline
\end{tabular}

that 6 of the 11 health behaviors are associated with the number of health exams; most of them are positively correlated, indicating that those individuals who incorporate healthy behaviors in their daily lives undergo health examinations more frequently. Although only four health behaviors are related to the other preventive healthcare behaviors (i.e., seeking medical care from the same physician), people in this population who incorporate healthy behaviors in their daily lives show a higher probability of seeing the same doctor. Additionally, four health behaviors correlate with the frequency of outpatient visits as well. However, having healthy behaviors might not definitely lead to a reduced frequency of outpatient visits. People who regularly exercise and measure their blood pressure appear to go to outpatient visits more frequently. After the adjustment of confounding variables, the results of the multivariate analysis show that there is a significant correlation between four health behaviors (i.e.,--having regular exercise habits, measuring blood pressure regularly, maintaining a low salt/low 
Table 3 The Regression Model of Healthcare Utilization

\begin{tabular}{|c|c|c|c|}
\hline \multirow[t]{2}{*}{ Variable } & Number of outpatient visits ${ }^{a}$ & Number of health exams ${ }^{b}$ & Seen by the same physicians \\
\hline & B $(95 \% \mathrm{Cl})$ & B $(95 \% \mathrm{Cl})$ & OR $(95 \% \mathrm{Cl})$ \\
\hline \multicolumn{4}{|c|}{ Exercise Habits } \\
\hline No & ${ }^{*}-0.39(-0.67,-0.11)$ & $* *-0.24(-0.33,-0.14)$ & **0.70 $(0.58,0.83)$ \\
\hline \multicolumn{4}{|l|}{ Breakfast } \\
\hline No & $0.06(-0.74,0.87)$ & $0.01(-0.26,0.27)$ & $1.06(0.64,1.74)$ \\
\hline \multicolumn{4}{|c|}{ Regular meals } \\
\hline No & $-0.06(-0.76,0.64)$ & $-0.03(-0.26,0.20)$ & $0.72(0.47,1.09)$ \\
\hline \multicolumn{4}{|c|}{5 servings of fruits\& vegetables } \\
\hline No & $0.46(-0.01,0.92)$ & $-0.06(-0.21,0.10)$ & $1.08(0.80,1.44)$ \\
\hline \multicolumn{4}{|c|}{ Dieting Habits } \\
\hline No & ${ }^{*} 0.53(0.02,1.53)$ & $-0.03(-0.19,0.14)$ & $0.92(0.67,1.25)$ \\
\hline \multicolumn{4}{|c|}{ Aware of food packaging labels } \\
\hline No & $-0.34(-0.89,0.21)$ & $-0.05(-0.23,0.14)$ & $0.87(0.62,1.23)$ \\
\hline \multicolumn{4}{|c|}{ Aware of self-health } \\
\hline No & $-0.12(-0.91,0.68)$ & $-0.08(-0.34,0.19)$ & $1.41(0.85,2.32)$ \\
\hline \multicolumn{4}{|c|}{ Regular BP checks } \\
\hline No & $*^{* *}-0.69(-0.98,-0.38)$ & $* *-0.31(-0.41,-0.21)$ & $0.95(0.79,1.14)$ \\
\hline \multicolumn{4}{|l|}{ Smoking } \\
\hline Yes & $0.24(-0.14,0.61)$ & $-0.09(-0.21,0.03)$ & $1.05(0.82,1.32)$ \\
\hline \multicolumn{4}{|l|}{ Drinking } \\
\hline Yes & $-0.01(-0.32,0.29)$ & $0.09(-0.01,0.19)$ & $* * 0.71(0.58,0.85)$ \\
\hline \multicolumn{4}{|c|}{ Betel-Nut chewing } \\
\hline Yes & $-0.30(-0.77,0.18)$ & $0.002(-0.15,0.16)$ & $1.27(0.94,1.70)$ \\
\hline
\end{tabular}

Data of gender, marital status, age, education levels, and diseases were adjusted ${ }^{*} p<0.05 ;{ }^{* *} p<0.001$

${ }^{2}=0.196$

${ }^{\mathrm{b}} R^{2}=0.136$

sugar/low fat diet, and having drinking habits) and the utilization of health care resources.

Regarding the utilization of preventive health care resources, individuals with a habit of exercise and performing blood pressure checks regularly have a higher tendency to undergo health exams, which corresponds with previous findings [22]; those who do not have drinking habits and those who have regular exercise regimens are more likely to seek medical care for illness from the same physician. Such results correspond to the findings of Qi, Phillips and Hopman (2006) [22]. The results demonstrate that the increased frequency of undergoing health exams and seeking the same physician for medical care may come with practicing healthy behaviors. Individuals require a remarkable level of motivation for self-health maintenance to continue regular daily exercise, blood pressure checks, and refrain from drinking. People who have a high motivation for keeping themselves healthy may discipline themselves to exercise and measure their blood pressure regularly, and to not consume alcohol. Also, these people understand the importance of undergoing health exams and seeking the same physician for medical care, and are thus more likely to perform these health behaviors and habits.

Additionally, there is a significant correlation between three health behaviors (i.e., having regular exercise habits, measuring blood pressure regularly,and maintaining a low salt/low sugar/low fat diet) and the frequency of outpatient visits. People who emphasize low salt, low sugar and low fat diets have fewer outpatient visits, which corresponds to the findings by Grisolia's (2013) [23]. However, having healthy behaviors might not definitely lead to a reduced frequency of outpatient visits. The individuals with regular exercise habits and blood pressure checks appear to have more outpatient visits. The people who exercise regularly might receive better overall long term health benefits $[19,22,24]$. Several researchers also claim that the warm-up and stretching movements is highly important prior to the actual exercise in order to avoid sports-related injuries [25-28]. People with sports-related injuries will look for rehabilitative treatments, and may lead to an increased number 
of outpatient visits. This study did not thoroughly investigate the types and intensity of exercise, hence it is uncertain that exercise definitely causes injuries; the answers are pending future research and discussion. In addition, people who regularly measure blood pressure might not be used to perform this measurement by themselves due to their unfamiliarity with the operation of the machine, thus, they may opt for outpatient consultation as an alternative and lead to an increased utilization of this health care service [22].

Besides health behaviors, gender, age, educational level, and health status have also been found to have a correlation with the utilization of health care resources. This study shows that women visit doctors more often and are more willing to go to the same physician for an illness, which corresponds to the findings of Middleton, Hing and $\mathrm{Xu}$ (2013) [29]. Fewer women receive health examinations than men, possibly because of the low percentage of women in the job market. Employers are legally required to provide health examination services to employees within the workplace, and because the employment rate for women is low, the chance of them receiving health examinations is reduced proportionally $[30,31]$. It is commonly hypothesized that the older the age, the poorer the health status, hence the frequency of outpatient visits and health exams is increased [32, 33]. The health policy in Taiwan provides regular health exam services for the middle-aged to senior population, increasing the opportunity for senior citizens to receive health examinations. There is a greater possibility for elderly people to seek medical care from the same physician when becoming ill [34]. The results of the multivariate analysis show that education levels have different effects on the frequency of outpatient visits and health exams. The welfare system of health insurance in Taiwan provide free health exams for a certain population and free oupatient visits for people with low social economical status. The results of this study show that the group with lower education levels has more outpatient visits and fewer health exams and is less likely to visit the same physician for illness. A possible reason is the lack of awareness of and demand for preventive healthcare, resulting in less desirable outcomes when health examinations are not obtained and not seeking medical care from the same physician. Most people with a lower educational level might also be categorized into people with lower SES (social economic status). People with lower SES have more privileges in terms of receiving health care services, however, people with a lower educational level, have limited knowledge of health care, that might have a negative effect on their health, and may result in an increased frequency of outpatient visits [22, 35-39]. The individuals suffering from disease have poorer health conditions, their number of doctor visits is higher compared with that of the individuals without diseases and they prefer to be seen by the same physician, which corresponds with previous findings [9]. Only the results from the univariate analysis showed correlations between marital status and the utilization of medical resources, although such correlations disappeared when confounding variables were controlled. Further research and validation are needed to understand the relationships between the variables. The limitation of this study is that the survey was only conducted in a regional city and the results of this study might not be able to generalize the trends as a global phenomenon.

\section{Conclusion}

This study was conducted to understand whether people with healthy behaviors have reduced utilization of health care resources. Results show that people with healthy behaviors have increased utilization of preventive healthcare services, that they undergo health exams more frequently and have a higher probability of seeking the same physician for medical care as well. However, thedecrease in the number of outpatient visits is not that significant in people with healthy behaviors. Specifically, people with regular exercise habits and with regular blood pressure measurement do outpatient visits more frequently. In Taiwan, free health exams are only provided once a year or once every 3 years. People should continue incorporating healthy behaviors in their daily routines in order to maintain their health. One can say that the preventive health care resources that are provided by the government have been obviously insufficient. It is strongly suggested that health consultation centers shall be set up in strategic places nationwide to ensure the proper delivery of health-related services (i.e., public education, basic BMI/blood pressure/blood sugar/ heart beat check-up, and consultation). Thus, people will be well-educated on the inculcation of healthy behaviors, the development and maximization of health care resources could be promoted, utilization of medical resources could be reduced and controlled, and lastly, the goal of public health may be achieved.

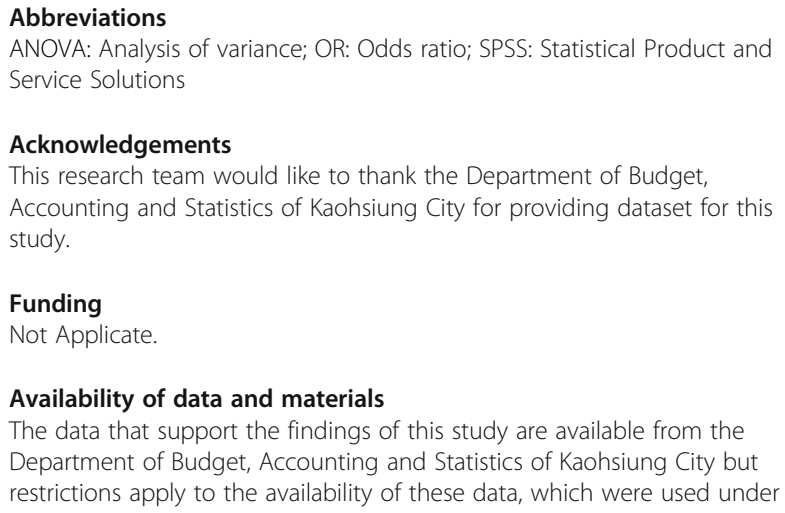


license for the current study, and so are not publicly available. Data are however available from the authors upon reasonable request and with permission of the Department of Budget, Accounting and Statistics of Kaohsiung City.

\section{Authors' contributions}

LIC defined the research theme and mainly contributed to study design, literature synthesis, statistical analysis, manuscript-writing and formation; CCS and DPL served as consultants in advanced statistical analysis, data interpretation and manuscriptrefinement. All authors read and approved the final version of the manuscript submitted for publication.

\section{Competing interests}

The authors declare that they have no competing interests.

\section{Consent for publication}

Not applicable.

\section{Ethics approval and consent to participate}

This study use the secondary data analysis which the data were derived from the data base of governmental department. These data-use has been granted an exemption from requiring ethics approval according to the regulations set by Ministry of Justice in Taiwan (updated http://mohwlaw.mohw. gov.tw/FLAW/FLAWDAT0202.aspx?lsid=FL066232).

\section{Publisher's Note}

Springer Nature remains neutral with regard to jurisdictional claims in published maps and institutional affiliations.

\begin{abstract}
Author details
${ }^{1}$ Department of Healthcare Administration and Medical Informatics, Kaohsiung Medical University, 100, Shih-Chuan 1st Road, Kaohsiung 807, Taiwan. ${ }^{2}$ Department of Hematology-Oncology, E-Da Cancer Hospital; School of Medicine for International Students, I-Shou University, No.21, Yi-Da Road, Jiao-Su Village, Yan-Chao District, Kaohsiung City 824, Taiwan. ${ }^{3}$ Department of Sport and Leisure, National Quemoy University, No.1, Daxue Rd., Jinning Township, Kinmen County, Kinmen 892, Taiwan.
\end{abstract}

Received: 29 December 2015 Accepted: 23 March 2017 Published online: 31 March 2017

\section{References}

1. Spencer DFT, Spencer BG. Chronic health conditions: changing prevalence in an aging population and some implications for the delivery of health care services. Can J Aging. 2010;29:11-21.

2. Hyeongsu K, Kunsei L, Sounghoon C, Gilwon K, Yangju T, Minjung L, et al. Factors affecting the validity of self-reported data on health services from the community health survey in Korea. YMJ. 2013;54:1040-8.

3. Kondilis E, Giannakopoulos S, Gavana M, lerodiakonou I, Waitzkin H, Benos A. Economic crisis, restrictive policies, and the population's health and health care: the Greek case. Am J Public Health. 2013;103:973-9.

4. Wasson JH, Sauvigne AE, Mogielnicki RP, Frey WG, Sox CH, Gaudette C, et al. Continuity of outpatient medical care in elderly men. J Amer Med Assoc. 1984:252:2413-7.

5. Kim J, Lee E, Lee T, Aeree S. Economic burden of acute coronary syndrome in South Korea: a national survey. BMC Cardiovasc Disord. 2013;13:1-8. doi: 10.1186/1471-2261-13-55.

6. Irizarry L, Li QE, Duncan I, Thurston AL, Fitzner KA, Edwards BJ, et al. Effects of cancer comorbidity on disease management: Making the case for diabetes education (A Report from the SOAR Program). Popul Health Manag. 2013;16:53-7.

7. National Health Insurance Administration. http://www.nhi.gov.tw/epaper/ ItemDetail.aspx?DatalD=3330\&|sWebData=0\&|temTypelD=5\&Papers|D= 289\&PicID. 2003. Accessed 2013.

8. Fuchs VR, McClellan MD, Skinner J. Area differences in utilization of medical care and mortality among US elderly. Cambridge: NBER Working Paper; 2001.

9. George PP, Heng BH, De Castro Molina JA, Wong LY, Wei Lin NC, Cheah JT. Self-reported chronic diseases and health status and health service utilization-Results from a community health survey in Singapore. Int J Equity Health. 2012;11:44-50. doi:10.1186/1475-9276-11-44.
10. Ohuabunwa U, Jordan Q, Seema S, Fost M, Flacker J. Implementation of a care transitions model for low-income older adults: a high-risk, vulnerable population. J Am Geriatr Soc. 2013;61:987-92.

11. Sartori AM, Novaes CG, de Soarez PC, Toscano CM, Novaes HM. Estimating health service utilization for treatment of pneumococcal disease: the case of Brazil. Vaccines. 2013;31:C94-8.

12. Andersen RM. Behavioral model of families' use of health service, Research Series, vol. NO.25. Chicago: Center for Health Administration Studies, University of Chicago; 1968.

13. Bishop TM, Willis MA. Healthcare utilization and symptom variationamong veterans using behavioral telehealth center services. J Behav Health Serv Res. 2013;40:416-26.

14. Wiley-Exley E, Domino ME, Ricketts TC, Cuddeback GB, Barbara J, Morrissey J. The impact of assertive community treatment on utilization of primary care and other outpatient health services the north carolina experience. J Am Psychiatr Nurses Assoc. 2013;19:195-204. doi:10.1177/1078390313494170.

15. Tsai MC, Lin SH, Chou YY, Lin SJ. Exploration of health status, healthcare utilization, and health service expectations among Taiwanese adolescents. Eur J Pediatr. 2014;173:187-96.

16. Bertakis KD, Azari R. Patient-centered care is associated with decreased health care utilization. J Am Board Fam Med. 2011;24(3):229-39.

17. Purvis DL, Lentino CV, Jackson TK, Murphy KJ, Deuster PA. Nutrition as a component of the performance triad: how healthy eating behaviors contribute to soldier performance and military readiness. US Army Med Dep J. 2013;66-78. https://www.researchgate.net/publication/258065715_The_ importance_of_leadership_in_Soldiers\%27_nutritional_behaviors_results_ from_the_Soldier_Fueling_Initiative_program_evaluation\#page.

18. Ford ES, Zhao G, Tsai J, Li C. Low-risk lifestyle behaviors and all-cause mortality: findings from the National Health and Nutrition Examination Survey III Mortality Study. Am J Public Health. 2011;101:1922-9.

19. Nualnim N, Parkhurst K, Dhindsa M, Tarumi T, Vavrek J, Tanaka H. Effects of swimming training on blood pressure and vascular function in adults $>50$ years of age. Am J Cardiol. 2012;109:1005-10.

20. Marshall VJ, Kalu N, Kwagyan J, Scott DM, Cain GE, Hill K, et al. Alcohol dependence and health care utilization in African Americans. J Natl Med Assoc. 2013;105:42-9.

21. McDonnell MN, Hillier SL, Hooker SP, Le A, Judd SE, Howard VJ. Physical Activity Frequency and Risk of Incident Stroke in a National US Study of Blacks and Whites. Stroke. 2013;44:2519-24.

22. Qi V, Phillips SP, Hopman WM. Determinants of a healthy lifestyle and use of preventive screening in Canada. BMC Public Health. 2006;6(1):275-82. doi: 10.1186/1471-2458-6-275.

23. Grisolia JM, Longo A, Boeri M, Hutchinson G, Kee F. Trading off dietary choices, physical exercise and cardiovascular disease risks. Soc Sci Med. 2013:93:130-8.

24. Trape AA, Jacomini AM, Muniz JJ, Sertorio JT, Tanus-Santos JE, do Amaral SL, et al. The relationship between training status, blood pressure and uric acid in adults and elderly. BMC Cardiovasc Disord. 2013;13:44-50. doi:10.1186/ 1471-2261-13-44.

25. Pollack KM, Kercher C, Frattaroli S, Peek-Asa C, Sleet D, Rivara FP. Toward environments and policies that promote injury-free active living - it wouldn't hurt. Health Place. 2012;18:106-14.

26. Mori Y, Tobina T, Shirasaya K, Kiyonaga A, Shindo M, Tanaka H. Long-term effects of home-based bench-stepping exercise training on healthcare expenditure for elderly Japanese. J Epidemiol. 2011;21:363-9.

27. Tan CM, Tan IW, Kok WL, Lee MC, Lee VJ. Medical planning for massparticipation running events: a 3-year review of a half-marathon in Singapore. BMC Public Health. 2014;14:1109. doi:10.1186/1471-2458-14-1109.

28. Carmont MR, Daynes R, Sedgwick DM. The impact of an extreme sports event on a district general hospital. Scott Med J. 2005;50(3):106-8.

29. Middleton K, Hing E, Xu J. National Hospital Ambulatory Medical Care Survey: 2005 outpatient department summary. Adv Data. 2007;389:1-34

30. Potvin L, Camirand J, Beland F. Patterns of health services utilization and mammography use among women aged 50 to 59 years in the Quebec Medicare system. Med Care. 1995;33:515-30.

31. Snider J, Beauvais J, Levy I, Villeneuve P, Pennock J. Trends in mammography and Pap smear utilization in Canada. Chronic Dis Can. 1996;17:108-17.

32. Middleton K, Hing E. National Hospital Ambulatory Medical Care Survey: 2003 outpatient department summary. Adv Data. 2005;366:1-36.

33. Joynt KE, Gawande AA, Orav EJ, Jha AK. Contribution of preventable acute care spending to total spending for high-cost Medicare patients. J Amer Med Assoc. 2013;309:2572-8. 
34. Weiss $L$, Blustein J. Faithful patients: the effect of long-term physicianpatient relationships on the costs and use of health care by older Americans. Am J Public Health. 1996;86:1742-7.

35. Zhang Q, Huang F, Liu Z, Zhang N, Mahapatra T, Tang W, Lei Y, Dai Y, Tang S, Zhang J. Cross-Cultural Validation of the High Blood Pressure Health Literacy Scale in a Chinese Community. Plos One. 2016;11(4):e0152182.

36. Ao X, Liu M, Gan Y, Wang H. Health literacy survey among permanent resident in Daxing District of Beijing. Wei Sheng Yan Jiu. 2014;43(1):73-7.

37. Javadzade SH, Sharifirad G, Radjati F, Mostafavi F, Reisi M, Hasanzade A. Relationship betweenhealth literacy, health status, and healthy behaviors among older adults in Isfahan, Iran. J Educ Health Promot. 2012;1:31. doi:10. 4103/2277-9531.100160.

38. Hong YJ, Yoon B, Shim YS, Cho AH, Lee ES, Kim YI, Yang DW. Effect of literacy and education on the visuoconstructional ability of non-demented elderly individuals. J Int Neuropsychol Soc. 2011:17(5):934-9.

39. Lecerof SS, Westerling R, Moghaddassi M, Östergren PO. Health information for migrants: the role of educational level in prevention of overweight. Scand J Public Health. 2011;39(2):172-8. doi:10.1177/1403494810395824.

Submit your next manuscript to BioMed Central and we will help you at every step:

- We accept pre-submission inquiries

- Our selector tool helps you to find the most relevant journal

- We provide round the clock customer support

- Convenient online submission

- Thorough peer review

- Inclusion in PubMed and all major indexing services

- Maximum visibility for your research

Submit your manuscript at www.biomedcentral.com/submit
Biomed Central 